\title{
Interpretações paleoambientais obtidas a partir das variações na coloração das carapaças de foraminíferos, da Enseada do Flamengo, SP
}

\author{
Wânia DULEBA
}

Instituto Oceanográfico da Universidade de São Paulo

(Caixa Postal 66149, 05389-970, São Paulo, SP, Brasil)

\begin{abstract}
- Abstract: Two cores obtained respectively from Saco da Ribeira and Saco do Perequê-Mirim, both located within Flamengo Bay, northern coast of São Paulo, Brazil, have been studied. At former site many pyrite- filled foraminifera carapaces were observed. At the other site, there occur carapaces filled with pyrite, as well as carapaces impregnated with limonite and iron monosulfide, the latter showing a close relationship between limonite and iron monosulfide impregnated carapaces with strongly bioturbated levels. These observations reveal more reducing conditions in the Saco da Ribeira than in the Saco do Perequê-Mirim. By quantifying the number of carapaces impregnated with hydroxide/oxide vs. those filled by ferrous sulfide, it was possible to estimate some differences in redox potencials at these two sites.

- Resumo: Dois testemunhos obtidos no Saco da Ribeira e Saco do PerequêMirim, locais situados na Enseada do Flamengo, foram estudados. No primeiro local foram observadas muitas carapaças de foraminíferos preenchidas por pirita. No outro local, além das carapaças preenchidas por pirita, foram notadas carapaças impregnadas com limonita e monossulfeto de ferro, as quais se relacionaram com níveis fortemente bioturbados. Essas informaçōes mostraram que o Saco da Ribeira é caracterizado por condiçōes mais redutoras do que no Saco do Perequê-Mirim. Através da quantificaçāo de carapaças de foraminíferos impregnadas com hidróxido/6xido e/ou preenchidos por sulfeto ferroso foi possível estimar algumas diferenças em potenciais de oxirreduçāo desses dois locais na Enseada do Flamengo.
\end{abstract}

- Descriptors: Foraminifers, Carapaces impregnated with limonite, Carapaces filled with pyrite, Potencial redox, Cores, Holocene, Reducing environment, Enseada do Flamengo: SP, Brasil.

- Descritores: Foraminíferos, Carapaças limonitizadas, Carapaças preenchidas por pirita, Pontencial de oxirredução, Testemunhos, Holoceno, Ambiente redutor, Enseada do Flamengo: SP, Brasil.

\section{Introdução}

Os foraminíferos, em geral, possuem carapaças calcárias esbranquiçadas ou aglutinadas pardacentas (Loeblich \& Tappan, 1964), mas, dependendo da presença

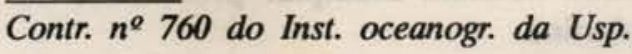

de algumas impurezas, como o ferro, as suas cores podem ser totalmente alteradas (Leāo \& Machado, 1989).

O ferro é insolúvel em ambiente marinho oxidante, ocorrendo em sedimentos superficiais sob a forma de limonita (hidróxido e/ou óxido de ferro) (Van Straaten, 1954). Quando precipitado sob estas condiçōes, o ferro pode modificar a coloração do sedimento e das carapaças, que adquirem tonalidades acastanhadas. 
Já, cm ambiente redutor, determinadas bactérias anacróbicas necessitam reduzir o sulfato para metabolizar a matéria orgânica disponível no sedimento (Leventhal, 1983). Como resultado desta reaçāo, o ácido sulfídrico é formado, que se espalha pelo sedimento por difusāo, reagindo diretamente com o ferro nas suas formas reativas. Desta reação, origina-se monossulfeto de ferro amorfo, denominado mackinawita (Sweeny \& Kaplan, 1973).

A partir da mackinawita outros monossulfetos de ferro, como pirrotita e greigita, podem ser formados dependendo da quantidade de enxofre clementar presente no meio (Berner, 1969). Uma vez precipitados, atribuem ao sedimento e às carapaças uma coloração preta ou acinzentada (Berner et al., 1979).

Estes monossulfetos transformam-se em pirita se permanecerem em ambiente redutor com altos teores de enxofre elementar. Entretanto, o tempo necessário à completa transformação do monossulfeto de ferro em pirita é da ordem de anos (Berner et al., op cit.), sendo a pirita, portanto, o sulfeto característico de sedimentos mais antigos.

Baseado nestes fatos, variaçōes na coloraçāo das carapaças de foraminíferos podem ser utilizadas em reconstruçōes paleoambientais (Maiklem, 1967) visto que, segundo Almasi (1978), estas variaçōes na coloração refletem a história deposicional e diagenética do sedimento.

$\mathrm{Na}$ tentativa de ampliar os conhecimentos sobre as história deposicional e diagenética dos sedimentos da Enseada do Flamengo, foram coletados e estudados dois testemunhos, de onde se procurou detectar variaçōes do potencial de oxirredução dos sedimentos, através da quantificação de carapaças impregnadas e/ou preenchidas com hidróxido/6xido ou sulfeto de ferro. Posteriormente, foram estabelecidas comparaçōes entre as variaçōes da coloração das carapaças, granulometria e teores de carbono orgânico dos sedimentos.

\section{Área de estudo}

As áreas estudadas (Fig. 1) situam-se no Saco da Ribeira e Saco do Perequê-Mirim da Enseada do Flamengo, Ubatuba, SP (23⒉ $29^{\prime} 42^{\prime \prime}$ a $23^{\circ} 31^{\prime} 30^{\prime \prime}$ 'S e $45^{\circ} 05^{\prime}$ a $45^{\circ} 0730^{\prime \prime} \mathrm{W}$ ).

A Enseada do Flamengo é pouco profunda, com profundidades máximas de $14 \mathrm{~m}$, com superfície de aproximadamente $18 \mathrm{~km}^{2}$ e largura média $2,5 \mathrm{~km}$, possuindo comunicaçāo direta com o mar aberto. É orientada na direção norte-sul, tendo, ao fundo, uma praia a nordeste denominada Praia da Enseada e duas pequenas baías: Saco do Perequê-Mirim, situado a norte, e o Saco da Ribeira, a noroeste (Fig. 1).
É um ambiente semiconfinado, cujo padrāo de circulaçāo caracteriza-se pela entrada de correntes vindas do sul, pelo lado ocidental da enseada. Estas correntes, após margearem a costa ocidental, bifurcam-se, indo para o Saco da Ribeira e costa oriental (Magliocca \& Kutner, 1965).

Esse padrão de circulaçāo condiciona a distribuição dos sedimentos de superfície de fundo, havendo deposiçāo de sedimentos mais grossos na costa ocidental e sedimentos mais finos no lado oriental da enseada (Mahiques, 1992).

\section{Material e métodos}

Os dois testemunhos analisados foram coletados a bordo do Barco de Pesquisa "Veliger II", do Instituto Oceanográfico da Universidade de Sāo Paulo, sob uma lâmina de água variável de 3 a $4 \mathrm{~m}$. Utilizando-se testemunhador à vibração foram obtidos o testemunho FLT01 (3,76 m), situado no Saco do Perequê-Mirim e, o testemunho FLT02 $(2,45 \mathrm{~m})$, localizado no Saco da Ribeira.

Em laboratório, os testemunhos foram descritos e amostrados em intervalos de $10 \mathrm{~cm}$, retirando-se seçōes de $1 \mathrm{e} 3 \mathrm{~cm}$ de espessura. A seção de $3 \mathrm{~cm}$ foi utilizada nas análises da coloração das carapaças de foraminíferos e granulométrica, ao passo que, a seção de $1 \mathrm{~cm}$ foi empregada nas análises de carbono orgânico.

As análises dos foraminíferos correspondem ao objeto de estudo deste trabalho, enquanto que, as análises sedimentológicas correspoderam a uma das etapas do trabalho de Mahiques (1992).

Dos dois testemunhos foram obtidas 44 amostras para o estudo das carapaças de foraminíferos, sendo que, de cada amostra foi retirada uma alíquota de $10 \mathrm{cc}$. Em seguida, todas as alíquotas foram lavadas e separadas em peneiras de $0,062 \mathrm{~mm}$, secas e submetidas à flotação com tetracloreto de carbono. Posteriormente as carapaças concentradas foram quarteadas e as limonitizadas e preenchidas por sulfeto de ferro foram quantificadas.

\section{Resultados}

Ao longo dos dois testemunhos analisados, desde a base até o topo, foram encontradas carapaças de foraminíferos preenchidas com sulfeto de ferro (pirita) (Figs 2 e 3). Estas carapaças preenchidas eram, na sua maioria, pertencentes à Subordem Rotaliina. Poucos exemplares pertencentes à Subordem Miliolina demonstraram estar preenchidos por pirita, ao passo que não foi encontrado nenhum exemplar preenchido da Subordem Textulariina. 


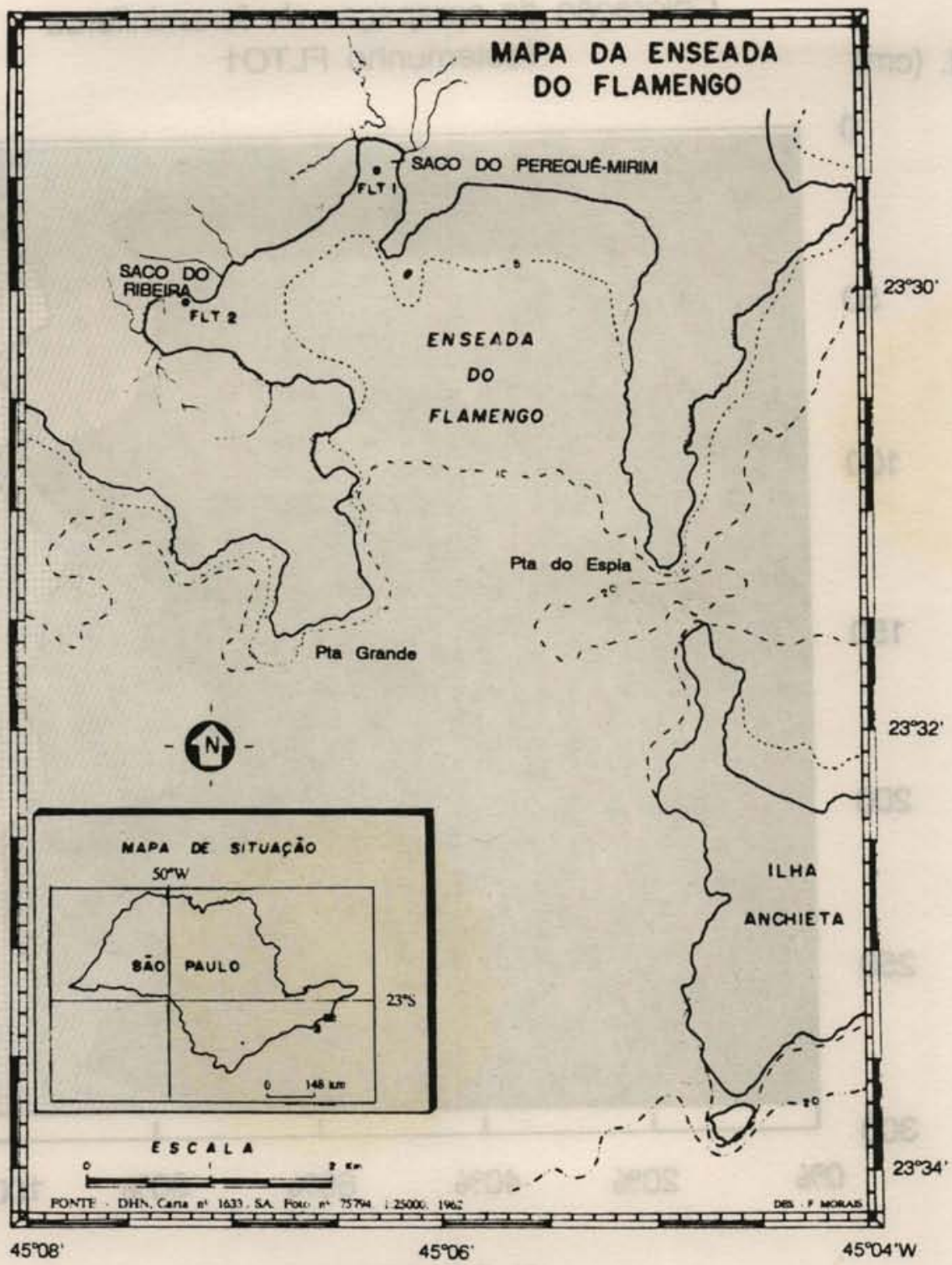

Fig. 1. Localização dos testemunhos na área de estudo.

Além disso, foram encontrados esferas de pirita soltas no sedimento em todos os intervalos dos dois testemunhos. Estas pequenas esferas assemelhavam-se texturalmente às esferas de pirita que preenchiam as carapaças, entretanto eram um pouco maiores.

Particularmente no testemunho FLT01, além da presença de carapaças preenchidas por pirita, foram observados vários padrōes de coloração das carapaças, tais como:

a) testas impregnadas, total ou parcialmente, por hidróxido e/ou óxido de ferro, de coloraçāo ocre escuro, ocre claro, ocre mosqueado ou listrada com branco, ocre e preto; b) testas impregnadas, total ou parcialmente, por monossulfeto de ferro, de coloração preta a cinza clara ou a combinação desta com branca.

A freqüência relativa destas carapaças coloridas variou bastante ao longo do testemunho FLT01, conforme pode-se constatar na Figura 2. Através desta figura observa-se que as testas com coloração normal (brancas) foram as mais abundantes, variando de 75 a $95 \%$ do total de carapaças das amostras analisadas. As testas preenchidas por pirita (douradas), estiveram presentes em todos os intervalos e, representaram cerca de 5 a $23 \%$ do número total de carapaças. Quanto às testas impregnadas por limonita (marrons), apesar de estarem ausentes no intervalo $62-70 \mathrm{~cm}$, variaram entre 1 a $17 \%$. As carapaças impregnadas por monossulfeto de ferro 


\section{Testemunho FLTO1}
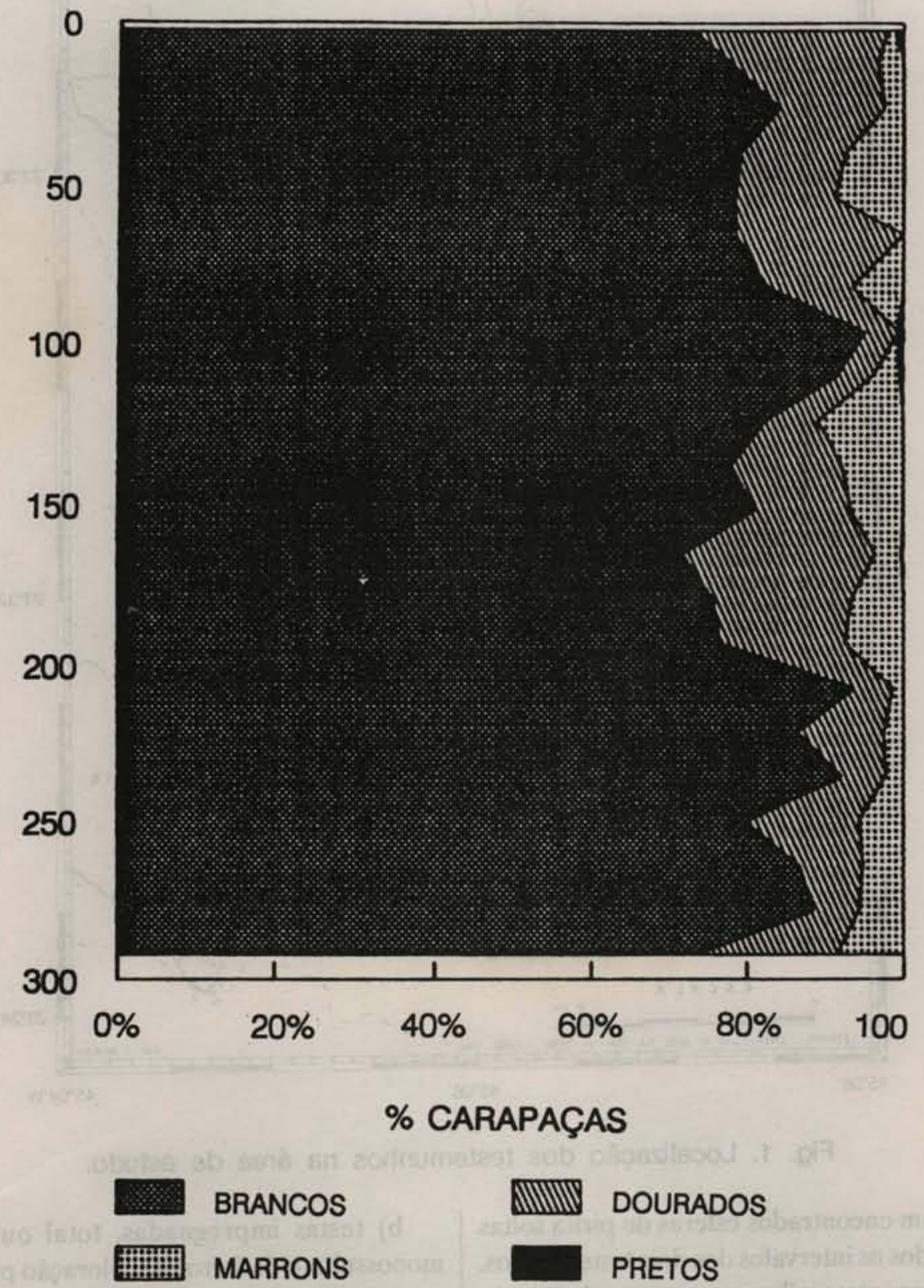

Fig. 2. Variação na coloração das carapaças de foramifferos do testemunho FLTO1.

(pretas) estiveram praticamente ausentes, restringindo-se apenas aos intervalos $81-84$ e 109-111 cm.

Dentre os exemplares de foraminíferos identificados no testemunho FLT01, a subordem Miliolina caracterizou-se por apresentar o maior número de exemplares com a coloraçāo ocre, apresentando grande variaçāo de tons amarronzados (Fig. 4). A subordem Rotaliina, caracterizou-se pelo preenchimento com pirita, tendo pouquíssimos exemplares impregnados por limonita e a subordem Textulariina nao apresentou padrōes coloridos.

\section{Discussão}

Foraminíferos preenchidos por pirita e pequenas esferas de pirita em sedimentos têm sido encontrados por vários autores (Love, 1962; Love \& Murray, 1966; Seiglie, 1973; Almasi, 1978; Leão \& Machado, 1989 e Raiswell et al., 1993), que ressaltam a importância da presença de ambiente redutor, para o aparecimento da pirita.

Além da presença de ambiente redutor para que a pirita se precipite, é necessário que haja quantidade suficiente de minerais detríticos de ferro, sulfato 


\section{Carapaças preenchidas por pirita FLTO2}

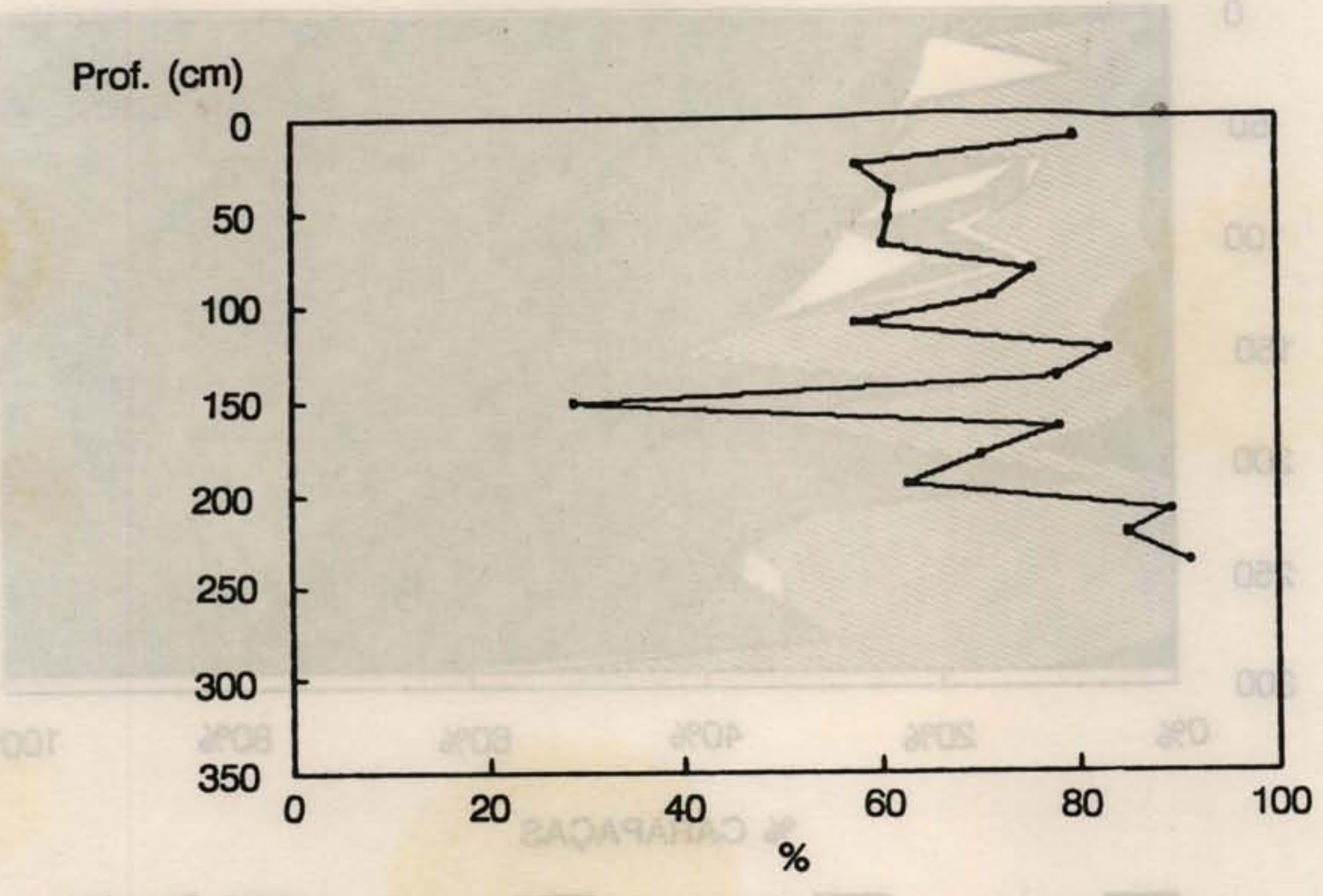

Fig. 3. Frequêencia relativa das carapaças piritizadas do testemunho FLTO2.

dissolvido, matéria orgânica e bactérias sulfato-redutoras (Golhaber \& Kaplan, 1974; Berner 1970, 1974). As porçōes mais internas da Enseada do Flamengo são ambientes propícios à precipitação do sulfeto de ferro, pois apresentam elevados teores de ferro (Magliocca \& Kutner, 1965), de carbono orgânico (Mahiques, 1992), de bactérias anaeróbicas (Candia-Hollnagel \& Duleba, 1993), quando comparados com os teores de outras enseadas de Ubatuba.

Das várias formas mineralógicas do sulfeto de ferro, descritas na literatura (Sweeny \& Kaplan, 1973; Rickard, 1970), a forma mais observada, ao longo dos testemunhos, foi a pirita com textura framboidal.

A pirita em sedimentos marinhos pode aparecer sob a forma framboidal ou de cristais simples, dependendo das condiçōes ambientais da sua formaçāo. Os processos que controlam a textura do sulfeto de ferro têm sido extensamente estudados por Sweeney \& Kaplan (1973), Rickard (1975), Goldhaber \& Kaplan (1974), Morse \& Corwell (1987) e Rainswell (1993). Tais autores têm demonstrado que, quando ambiente é completamente anóxico, desprovido de qualquer atividade biológica, com sedimentos de $\mathrm{pH}$ muito baixo, e altas concentraçōes de outros tipos de metais, a pirita é precipitada sob a forma de cristais distintos. Já os ambientes não completamente anóxicos (Sweeny \& Kaplan, op cit.) e que apresentam íon férrico e greitita, propiciam a precipitação de pirita framboidal.

A simples presença de pirita, que ocorreu dentro das carapaças de foraminíferos ou como esferas soltas no sedimento, pode indicar que as condiçōes ambientais, ao longo dos testemunhos analisados, foram predominantemente redutoras e, a partir da textura framboidal da pirita pode-se inferir que o ambiente nao deveria ser totalmente anóxico, apresentando algum padrão de circulaçāo.

Ao longo do testemunho FLT02, as porcentagens de carapaças preenchidas por pirita foram muito elevadas, sugerindo que o Saco da Ribeira sempre apresentou características redutoras neste intervalo do Holoceno. Particularmente no meio deste testemunho entretanto, houve declínio acentuado destas carapaças preenchidas, demonstrando portanto, mudanças nas condiçōes ambientais. 
Prof. (cm)

\section{Coloração de Miliolídeos}

Testemunho FLTO1



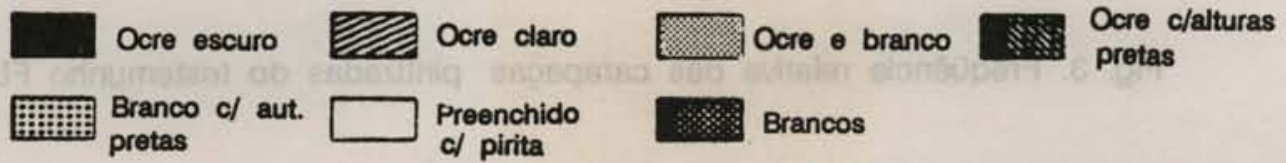

Fig. 4. Variação na coloração das carapaças de miliolíneos do testemunho FLTO1.

Apesar de ter se observado carapaças preenchidas por pirita em todos os intervalos nos dois testemunhos cabe ressaltar que, ao longo do testemunho FLT01 foram encontrados vários tipos de coloração de carapaças, havendo inclusive algumas carapaças limonitizadas, as quais sāo indicadoras de ambientes oxidantes.

As diferenças encontradas nos dois testemunhos permitem inferir que os dois locais estudados, embora ambos redutores, diferem entre si. O Saco do Perequê-Mirim deve ser pouco mais oxigenado que oSaco da Ribeira. Isto talvez ocorra em função da circulação da primeira regiāo ser menos restrita que a segunda.

Os dados de granulometria destes dois testemunhos (Mahiques, 1992), corroboram estes dados. No testemunho FLT02 os teores de lama sempre foram elevados da base até o topo, sugerindo ambiente mais calmo, enquanto que no testemunho FLT01 foram observados teores mais elevados de areia, indicando ambiente com circulaçāo mais efetiva.

Duleba \& Eichler (1993), estudando os tamanhos das carapaças de foraminiferos subrecentes das porçōes mais internas da Enseada do Flamengo, demonstraram que o Saco do Perequê-Mirim é mais oxigenado que o Saco da Ribeira, pois somente na primeira regiāo é que foram encontradas carapaças muito maiores que $300 \mu \mathrm{m}$.

Quanto aos outros padrōes encontrados no testemunho FLT01 foram observadas várias carapaças limonitizadas, algumas carapaças impregnadas por monossulfeto e outras com padrão mosqueado (Figs $2 \mathrm{e}$ 4). A limonita presente nas carapaças pode ter sido precipitada no próprio Saco do Perequê-Mirim, por este local apresentar condiçōes mais oxigenadas, e/ou estas carapaças podem ter sido transportadas. Tanto a pirita quanto o monossulfeto se precipitam em ambiente redutor, já a limonita precipita-se em ambiente oxidante, 
em ambiente geralmente emerso. Portanto, é possível que as carapaças impregnadas por monossulfeto e as preenchidas por pirita sejam autóctones, ao passo que as carapaças limonitizadas pertençam à sedimentos retrabalhados e remanescentes de períodos de regressōes marinhas. Quanto ao padrão mosqueado, este foi encontrado somente nas carapaças de miliolíneos. Tal fato estaria relacionado à microestrutura destas carapaças, que propicia uma maior ação do agente corante (Maiklem, 1967). Este corante pode localizar-se ao longo das linhas de junçāo das câmaras, dando aspecto listrado, preencher a maioria dos microporos, ou ainda preencher as aberturas e as câmaras vazias (Leão \& Machado, 1989).

Além destes padrōes foi observado uma ocorrência pouco significativa de carapaças pretas e uma freqüência considerável de carapaças ocres e douradas. Isto pode sugerir que quase todo o monossulfeto de ferro pode ter sido transformado em óxido e/ou hidróxido de ferro (Fig. 2). De acordo com Maiklem (1967), carapaças pretas, através de processos erosivos ou pela ação de agentes bioturbadores, podem ser transportadas do ambiente redutor para o oxidante, tornando-se amarronzadas, visto que, o monossulfeto de ferro presente nas testas é transformado em óxido e/ou hidróxido de ferro.

O testemunho FLT01, de acordo com a descriçāo macroscópica de Mahiques (1992), apresentou bioturbaçōes em vários intervalos, sendo que estes intervalos geralmente coincidiram com os intervalos aonde ocorreram as maiores porcentagens de carapaças amarronzadas (Fig. 5). Próximos a estes intervalos foram encontradas carapaças de miliolíneos ocres com pequenas manchas pretas na região apertural, sugerindo processo transitório entre monossulfeto e hidróxido/ óxido de ferro.

As carapaças impregnadas por monossulfeto de ferro, além de terem sido transformadas em hidróxido/óxido de ferro, podem ter sido transformadas em sulfeto de ferro. Sudgen (1966) afirma que, se as testas pretas permanecerem em ambiente redutor, podem transformar-se em carapaças piritizadas, pois o monossulfeto de ferro corresponde a um estágio intermediário na formação da pirita.

Com relação ainda à presença conspícua de carapaças piritizadas e à baixíssima ocorrência de carapaças impregnadas por monossulfeto de ferro, tais dados podem estar relacionados à salinidade do ambiente deposicional. Berner et al. (1979) têm demonstrado correlaçōes razoáveis entre a salinidade do ambicnte deposicional e as taxas de sulfeto de ferro/monossulfeto de ferro dos sedimentos. 0 processo de formação da pirita, como foi citado anteriormente, depende de determinadas quantidades de sulfato dissolvido, ferro reativo, e de matéria orgânica. Entretanto, ambientes com baixas salinidades possuem quantidades reduridas de sulfato dissolvido na água. Em tais ambientes, há grandes quantidades de monossulfeto, visto que a transformaçāo de monossulfeto em pirita é impedida, devido à deficiência de sulfato nas águas intersticiais. Já em ambientes marinhos, a pirita $\hat{e}$ a forma dominante do sulfeto de ferro, porque o sulfato não é um fator limitante.

Baseado nestes dados de Berner et al. (op cit.) pode-se deduzir que os sedimentos analisados do testemunho FLT02 foram predominantemente depositados em ambiente com salinidade marinha normal. Quanto ao testemunho FLT01, as poucas carapaças impregnadas por monossulfeto (em determinados intervalos) podem sugerir que apesar dos sedimentos terem sido depositados em ambiente com salinidade normal, $\mathrm{o}$ aporte do rio Perequê-Mirim deve ter sido mais proeminente nestes intervalos.

\section{Conclusōes}

1) As condiçōes ambientais que prevaleceram, ao longo dos dois testemunhos estudados, foram predominantemente redutoras, contudo não completamente anóxica, talvez em funçāo de circulação restrita de água.

2) Dos dois testemunhos analisados somente o testemunho FLT01, coletado no Saco do Perequê-Mirim, apresentou além da cor dourada devida à pirita, outros tipos de coloraçāo, como carapaças ocres (limonitizadas) e carapaças pretas (monossulfeto de ferro).

3) A presença de carapaças limonitizadas, assim como os dados granulométricos e de carbono orgânico, sugerem que o Saco do Perequê-Mirim deve possuir uma circulaçāo mais acentuada que o Saco da Ribeira.

4) O número reduzido de carapaças pretas deve-se talvez ao fato destas carapaças terem sido transformadas em carapaças limonitizadas ou preenchidas por pirita, ou provavelmente porque os sedimentos foram depositados em ambientes com salinidade normal.

5) O testemunho FLT01 apresentou várias carapaças limonitizadas, que podem estar relacionadas à sedimentos provenientes de regressōes marinhas, ou estas também podem ter sido originalmente impregnadas por monossulfeto de ferro e posteriormente ter sido trazidas à superfície por organismos bioturbadores. 







\section{Agradecimentos}

A Dra Beatriz Beck Eichler pelas oportunidades oferecidas e aos Drs Kenitiro Suguio, Michel M. de Mahiques e Moysés G. Tessler pela leitura e crítica do manuscrito. A Dra Altair de Jesus Machado (UFBa) pelos trabalhos enviados.

\section{Referências bibliográficas}

ALMASI, M. N. 1978. Ecology and variation of benthic Foraminifera in Barnes Sound, Northeast Florida Bay. Ms. Thesis, Univ. of Miami, Florida, USA 144p.

BERNER, R. A. 1969. Migration of iron and sulfur within anaerobic sediments during early diagenesis. Am. Jour. Science, 267:19-42.

1970. Sedimentary pyrite formation. Am. Jour. Science, 268:1-23.

BERNER, R. A. 1974. Iron sulfides in Pleistocene deep Black Sea sediments and their paleo-oceanographic significance: In: Degens, E.T. \& Ross, D. A. eds The Black Sea - Geology, Chemistry, and Biology. Am. Assoc. Petroleum Geologist Mem., 20:524-531.

; BALDWIN, T. \& JR-HOLDREN, G. R. 1979. Authigenic iron sulfides as paleosalinity indicators. Jour. Sedim. Petrol., 49: 1345-1350.

CANDIA-HOLLNAGEL, H. \& DULEBA, W. 1993. Estudos preliminares da ocorrência do gênero Clostridium em testemunho na Enseada do Flamengo, Ubatuba (lat. $23^{\circ} 30^{\prime} \mathrm{S} 45^{\circ} 09^{\prime} \mathrm{W}$ ), Brasil. In: SIMPÓSIO SOBRE ECOSSISTEMAS DA COSTA BRASILEIRA, 3., Serra Negra, 1993. Resumo, Academia de Ciências do Estado de São Paulo.

DULEBA, W. \& EICHLER, B. B. 1993. Caracterização paleoambiental da Enseada do Flamengo, a partir da variação do tamanho das carapaças de foraminíferos. In: CONGRESSO DA ABEQUA, 4., São Paulo, Associação Brasileira de Estudos do Quaternário, 1:39.

GOLDHABER, M. B. \& KAPLAN, I. R. 1974. The sulfur cycle, In: Goldberg, E.D. ed., The Sea: New York, Wiley, 569-655.

LEÄO, Z. M. A. \& MACHADO, A. J. 1989. Variação da cor dos grãos carbonáticos de sedimentos marinhos atuais. Revta Bras. Geoc., 19(1):87-91.
LEVENTHAL, J. S. 1983. An interpretation of carbon and sulfur relationship in Black Sea sediments as indicators of environment of deposition. Geochim. Cosmochim. Acta, 47:133-137.

LOEBLICH, A. R. \& TAPPAN, H. 1964. Protista. In: Moore, R. C. ed. 1964. Treatise on invertebrate paleontology, Part C. New York, The University Kansas Press, 2v.

LOVE, L. C. 1962. Further studies on micro-organisms and the presence of syngenetic pyrite. Paleon., 5:444-459.

\& MURRAY, J. W. 1963. Biogenic pyrite in recent sediments of Christchurch Harbour, England. Am.Jour.Sci., 261:433-448.

MAGLIOCCA, A. \& KUTNER, A. S. 1965. Sedimentos de fundo da Enseada do Flamengo Ubatuba. Bolm Inst. oceanogr., S Paulo, 8: 1-14.

MAHIQUES, M. M. de 1992. Variaçōes temporais na sedimentação holocênica dos embaiamentos da regiāo de Ubatuba (SP). Tese de doutorado. Universidade de São Paulo, Instituto Oceanográfico. $2 \mathrm{v}$.

MAIKLEM, W. R. 1967. Black and brown speckled foraminiferal sand from the southern part of the Great Barrier reef. J. sedim. Petrol., 37(4):1023-1030.

MORSE, J. W. \& CORNWELL, J. C. 1987. Analysis and distribution of iron sulfide minerals in recent anoxic marine sediments. Mar. Geol., 22:55-69.

RAISWELL, R; WHALER, K.; DEAN, S.; COLEMAN, M. L. \& BRIGGS, D. E. G. 1993. A simple three-dimensional model of diffusion- withprecipitation applied to localised pyrite formation in framboids, fossil and detrital iron minerals. Mar. Geol., 113:89-100.

RICKARD, D. T. 1970. The origin of framboids. Lithos, 3:260-293.

1975. Kinetics and mechanism of pyrite formation at low temperatures. Am. Jour. Scien., 275:639-652.

SEIGLIE, G. A. 1973. Pyritization in living foraminifers. J. foram. Res., 3:1-6.

SUDGEN, W. 1966. Pyrite stainning of pellety debris in carbonate sediments from the Middle East and elsewhere. Geol. Mag., 193(3):250-256. 
SWEENEY, R. E. \& KAPLAN, I. R. 1973. Pyrite framboid formation: laboratory synthesis and marine sediments. Econ. Geol., 68:618-634.

Van STRAATEN, L. J. V. 1954. Composition and structure of recent sediments in the Netherlands. Leidse Geol. Medel, Leiden, 19:1-110.

(Manuscrito recebido 10 fevereiro 1994; revisado 15 junho 1994; aceito 27 setembro 1994) 